\title{
Association between the frequency of surgeries for video-assisted thoracic surgery and the incidence of consequent surgical site infections: a retrospective observational study based on national surveillance data
}

Toshiki Kajihara ${ }^{1 *}$, Koji Yahara ${ }^{1}$, Aki Hirabayashi ${ }^{1}$, Hitomi Kurosu', Motoyuki Sugai ${ }^{1}$ and Keigo Shibayama ${ }^{2}$

\begin{abstract}
Background: The association between the frequency of surgeries and the incidence of surgical site infections (SSIs) has been reported for various surgeries. However, no previous study has explored this association among videoassisted thoracic surgeries (VATS). Hence, we aimed to investigate the association between the frequency of surgeries and SSI in video-assisted thoracic surgeries.
\end{abstract}

Methods: We analyzed the data of 26,878 thoracic surgeries, including 21,154 VATS, which were collected during a national surveillance in Japan between 2014 and 2018. The frequency of surgeries per hospital department was categorized into low (<50/year), moderate (50-100/ year), and high ( $>100 /$ year). Chi-squared test or Fisher's exact test was used for discrete explanatory variables, whereas Wilcoxon's rank-sum test or Kruskal-Wallis test was used for continuous explanatory variables. Univariate analysis of the department groups was conducted to explore confounding factors associated with both SSIs and the department groups. We used a multiple logistic regression model focusing on VATS and stratified by the National Nosocomial Infections Surveillance System (NNIS) risk index.

Results: The rates of SSIs in the hospital groups with low, moderate, and high frequency of surgeries were 1.39, 1.05 , and $1.28 \%$, respectively. In the NNIS risk index 1 stratum, the incidence of SSIs was significantly lower in the moderate-frequency of surgeries group than that in the other groups (odds ratio [OR]: vs. low-frequency of surgeries: 2.48 [95\% confidence interval [Cl]: 1.20-5.13], $P=0.0143$; vs. high-frequency of surgeries: 2.43 [95\% Cl: 1.44-4.11], $P=0.0009$ ). In the stratum of NNIS risk indices 2 and 3, the incidence of SSI was significantly higher in the low-frequency of surgeries group (OR: 4.83, 95\% Cl: 1.47-15.93; $P=0.0095)$.

* Correspondence: kajihara@nih.go.jp

${ }^{1}$ Antimicrobial Resistance Research Center, National Institute of Infectious Diseases, 4-2-1 Aoba-cho Higashimurayama, Tokyo 189-0002, Japan

Full list of author information is available at the end of the article

C C The Author(s). 2021 Open Access This article is licensed under a Creative Commons Attribution 4.0 International License, which permits use, sharing, adaptation, distribution and reproduction in any medium or format, as long as you give appropriate credit to the original author(s) and the source, provide a link to the Creative Commons licence, and indicate if changes were made. The images or other third party material in this article are included in the article's Creative Commons. licence, unless indicated otherwise in a credit line to the material. If material is not included in the article's Creative Commons licence and your intended use is not permitted by statutory regulation or exceeds the permitted use, you will need to obtain permission directly from the copyright holder. To view a copy of this licence, visit http://creativecommons.org/licenses/by/4.0/ The Creative Commons Public Domain Dedication waiver (http://creativecommons.org/publicdomain/zero/1.0/) applies to the data made available in this article, unless otherwise stated in a credit line to the data. 
(Continued from previous page)

Conclusion: The result suggests that for departments with low-frequency of surgeries, an increase in the frequency of surgeries to > 50 per department annually potentially leads to a decrease in the incidence of SSIs. This occurs through an increase in the experience of the departmental surgeons and contributes to the improvement of VATS outcomes in thoracic surgeries.

Keywords: Surgical site infection, Frequency of surgeries, Video-assisted thoracic surgery, National surveillance, Epidemiology

\section{Background}

Thoracic surgery (THOR) is a standard modality for early non-small cell lung cancer and recurrent pneumothorax. Video-assisted thoracic surgery (VATS) has been widely used to treat lung cancer and pneumothorax in the past two decades because of its minimally invasive technique [1]. In Japan, in 2018, the number of lung cancer operations using VATS was 34,249 and accounted for $75.7 \%$ of the total operations $(n=45,243)$, whereas that of pneumothorax-related operations using VATS was 14,379 and accounted for $97.6 \%$ of the total operations $(n=14,731)$ [2].

Surgical site infections (SSIs) remain among the most frequent healthcare-associated infections worldwide [3]. In the European point prevalence survey between 2016 and 2017, the incidence of SSIs was 18.3\% [4], and the estimated number of related deaths per year was 16,049 in the European Union [5]. The cost of healthcare-related infections amounted to US $\$ 17,916$ for colon surgeries and US $\$ 34,741$ for coronary artery bypass graft surgeries [6]. In this context, preventing SSI not only leads to good patient outcome, but also has economic benefits [7]. In thoracic surgery, SSIs are also associated with increased morbidity, in-hospital mortality, prolonged hospitalization, and increased costs [8]. There are various reports of risk factors for SSI, for example, age, sex, smoking, body mass index, duration, American Society of Anesthesiology score, wound class, emergency operation, which depend on the types of surgeries performed [9]. VATS has improved the incidence of postoperative complications, and thus, has been increasingly used in thoracic surgeries [10].

The association between the frequency of surgeries per department and the incidence of SSI in various surgeries is yet to be clarified because findings have been conflicting. As an influencing factor of the incidence of SSI, a previous study showed that surgeons with a higher frequency of surgeries (i.e., surgeons with a large number of surgeries conducted per period) tended to be associated with a lower incidence rate of SSIs than their colleagues with a lower frequency of surgeries [11, 12]. Further, departments with a higher frequency of surgeries were associated with better patient outcomes [1315]. In contrast, Furuya-Kanamori et al. reported that groups with high-frequency of surgeries tended to have a higher risk of encountering SSIs than groups with lowfrequency of surgeries in colorectal surgeries [16]. Specifically, there has been no study focusing on videoassisted thoracoscopic surgery (VATS). The association between the frequency of VATS and the incidence rate of SSIs remains unknown.

To investigate the association between the frequency of surgeries and SSIs in video-assisted thoracic surgeries, we utilized a subset of the national SSI surveillance data collected in Japan, where surveillance for SSIs has been conducted since 2002 as the Japan Nosocomial Infections Surveillance (JANIS) [17, 18], which is one of the largest SSI databases.

\section{Methods \\ Study design and data source}

This retrospective observational study extracted the surveillance data of patients who underwent THOR between 2014 and 2018, from the JANIS database. Briefly, the JANIS database includes data on 305,960 surgeries from 802 institutions in 2018. The SSI surveillance in JANIS is conducted using the definition of the US National Nosocomial Infections Surveillance System (NNIS), with some modifications. It is comparable to other international SSI surveillances, such as the OPKISS of Germany [19] and the National Healthcare Safety Network of the United States of America [20]. THOR data using only cardiac or cardiovascular surgeries were not included in the JANIS database. Patient information is de-identified by each hospital before submission to the JANIS database. Hospitals are recruited on a voluntary basis each year for the JANIS, and the participating hospitals are required to report SSI surveillance data for selected operative procedures electronically on a biannual basis [21].

\section{Data collection}

In total, 247 departments across 247 hospitals (each hospital has one thoracic surgery department) participated in the JANIS SSI surveillance for at least 1 year from 2014 to 2018. They submitted the data of 39,368 THOR procedures during the period. The data of 26,878 cases of THOR performed in 74 hospitals, which completed 
data submission during the 5 years (from 2014 to 2018), were included in the present study.

The variables analyzed included NNIS risk index, age, sex, multiple procedures, emergency operation, implant, trauma surgery, general anesthesia, and video-assisted surgery. The United States Center for Disease Control defines the NNIS risk index as the sum of three binary variables indicating whether 1) the American Society of Anesthesiologist score is higher than two, 2) wound classification is contaminated or dirty, and 3) duration of the procedure in minutes is longer than the 75th percentile. It is a convenient risk stratification system widely used worldwide, including in the JANIS [22]. The departments were classified into three department groups according to the frequency of surgeries (i.e., the average number of procedures per department per year) as low $(<50 /$ year), moderate (50-100/year), and high ( $>100 /$ year) based on its distribution (Additional Fig. 1) according to a previous study [23].

\section{Statistical analysis}

Potential risk factors for SSI were first explored using univariate analysis. Chi-squared test or Fisher's exact test were used for discrete explanatory variables, whereas Wilcoxon's rank-sum test or Kruskal-Wallis test were used for continuous explanatory variables. A univariate group analysis of the department groups was conducted to explore confounding factors associated with both SSIs and the department groups. Multiple logistic regression analysis was performed to estimate the odds ratios (ORs) and $95 \%$ confidence intervals (CIs) of the risk factors after adjusting for confounding factors. We fitted the multiple logistic regression model stratified by the NNIS risk index after grouping risk indices 2 and 3 into a stratum for clear interpretation. The stratification was conducted using the NNIS risk index rather than the three binary variables comprising it because they were highly correlated with each other: variable 2) was highly significantly associated with variables 1) and 3) $(p<$ 0.001 ), and there was a significant association between variables 1$)$ and 3) $(p=0.015)$. All statistical analyses were performed using JMP Version 13.2.1 (SAS Institute, Cary, NC, USA). A $P$ value $<0.05$ was considered statistically significant.

\section{Ethical considerations}

Patient identifiers were de-identified by each hospital before data submission to JANIS. The anonymous data stored in the JANIS database were exported and analyzed.

The protocol of this study was approved by the Ministry of Health, Labor and Welfare (approval number 0417-1) according to Article 32 of the Statistics Act and in accordance with the Helsinki Declaration. The requirement for informed consent was waived by the Ministry of Health, Labor and Welfare (approval number 0417-1).

\section{Results}

Total incidence of SSIs in the THOR procedures and their characteristics

The total number and rate of SSIs in the THOR procedures during the study period were 335 and $1.25 \%$, respectively (Table 1). A total of 21,154 VATS procedures were performed, accounting for $78.7 \%$ of all THOR procedures. The number of VATS procedures was approximately four times greater than that of open thoracic surgeries. There were 17,615 (65.5\%) male patients. The most dominant SSI was organ/space SSI (48.4\%), followed by superficial incisional infections (38.2\%). Causative pathogens were identified in $59.4 \%$ of all cases, with the most common being methicillin-resistant Staphylococcus aureus infection (64 isolates), followed by methicillin-susceptible $S$. aureus infection (54 isolates). The most common causative gram-negative bacterium was Pseudomonas aeruginosa (14 isolates). Polymicrobial infections were found in 30 cases.

\section{Classification of departments by the frequency of surgeries}

A median of 47.8 (Inter Quartile Range: 11.4-110.4) procedures (the frequency of surgeries per department) were conducted per year. The distribution among the 74 departments is shown in Additional Fig. 1. In total, 38, 16 , and 20 departments were classified as the centers of low-, moderate-, and high-frequency of surgeries, respectively. A total of 3086 (11.5\%), 5718 (21.3\%), and 18, 074 (67.2\%) THOR procedures were conducted in these departments annually, and the median numbers were 11.8, 68.6, and 145.2, respectively. A comparison of the three department groups (Table 2) revealed statistically significant differences in the number of beds $(P<0.0001$, Kruskal-Wallis test), teaching hospitals $(P=0.0012$, Fisher's exact test), and tertiary hospitals $(P=0.0074$, chi-square test). All four teaching hospitals were included in the group with a high-frequency of surgeries, which accounted for $20 \%$ of the hospitals in this group. Meanwhile, the tertiary hospitals accounted for 13.2, 37.5 , and $50 \%$ of the hospitals in the groups with low-, moderate-, and high-frequency of surgeries, respectively.

Univariate analysis of risk and confounding factors of SSI As indicated above, VATS accounted for the majority (78.7\%) of THOR procedures. We also found a statistically significant difference in the proportion of procedures using VATS among the three department groups (72.7, 81.6, and $78.8 \%, P<0.0001$, chi-square test) and in the rate of SSI between VATS and other procedures 
Table 1 Descriptive statistics of the procedures, patients, and SSI

\begin{tabular}{|c|c|c|}
\hline Total no. of procedures (from 2014 to 2018) among the 74 departments & 26,878 & \\
\hline Video-assisted thoracic surgery & 21,154 & \\
\hline Open thoracic surgery & 5724 & \\
\hline Emergency surgery & 1569 & \\
\hline Mean age & 62.1 & $(0-97)$ \\
\hline Male sex (\%) & 17,615 & $(65.5)$ \\
\hline Incidence of SSI, N (\%) & 335 & $(1.25)$ \\
\hline \multicolumn{3}{|l|}{ Type of SSI, N (\%) } \\
\hline Superficial incisional & 128 & $(38.2)$ \\
\hline Deep incisional & 45 & $(13.4)$ \\
\hline Organ/space & 162 & $(48.4)$ \\
\hline \multicolumn{3}{|l|}{ Type of specimen } \\
\hline Superficial/deep incisional site drainage & 102 & \\
\hline Organ/space drainage & 97 & \\
\hline Sputum & 12 & \\
\hline Blood & 7 & \\
\hline Respiratory specimen & 6 & \\
\hline Other drainage & 2 & \\
\hline Tissue & 1 & \\
\hline Other & 3 & \\
\hline \multicolumn{3}{|l|}{ Causative pathogens } \\
\hline MRSA & 64 & \\
\hline MSSA & 54 & \\
\hline Streptococcus spp. & 17 & \\
\hline Pseudomonas aeruginosa & 14 & \\
\hline Corynebacterium spp. & 12 & \\
\hline CNS & 10 & \\
\hline Staphylococcus epidermidis & 7 & \\
\hline Enterococcus faecalis & 6 & \\
\hline Escherichia coli & 4 & \\
\hline Klebciella pneumoniae & 4 & \\
\hline Others & 26 & \\
\hline Polymicrobial & 30 & \\
\hline
\end{tabular}

CNS central nervous system, MRSA Methicillin-resistant Staphylococcus aureus, MSSA methicillin-susceptible Staphylococcus aureus, SSI surgical site infections

(1.11 and $1.75 \%, P=0.0001$, chi-square test). These results indicated that VATS was a confounding factor significantly associated with both the department groups and the rate of SSI. To control for its effect in examining the association between them, we confined the procedures using VATS in the following analyses.

Descriptive statistics calculated from the data of the VATS procedures are shown in the middle and end of Table 2. In total, 2245, 4667, and 14,242 VATS procedures were performed in the groups with low-, moderate-, and high-frequency of surgeries, respectively. Meanwhile, 33 (1.47\%), 35 (0.75\%), and 167 (1.17\%) SSIs occurred in the above groups, respectively. There were significant differences in age $(P<0.0001$, Kruskal-Wallis test), number of male patients $(P<0.0001$, chi-square test), emergency operations $(P<0.0001$, chi-square test), and NNIS risk index $(P<0.0001$, chi-square test) among the groups (Table 2$)$.

Regarding risk factors for SSIs, we found a significantly higher risk in men $(P<0.0001$, chi-square test, $1.33 \%$ in men, vs. $0.69 \%$ in women) and in those with an NNIS risk index of 2-3 $(P<0.0001$, chi-square test; risk index $0,0.71 \% ; 1,1.80 \%$; and $2-3,3.80 \%])$. This indicated that sex and the NNIS risk index, in addition to VATS, were the confounding factors. 
Table 2 Classification of departments in terms of frequency of surgeries, and univariate analysis of risk and confounding factors of SSI

\begin{tabular}{|c|c|c|c|c|c|c|}
\hline & \multirow[b]{3}{*}{ total } & \multicolumn{3}{|c|}{$\begin{array}{l}\text { Department groups in terms of average number of all } \\
\text { kinds of procedures/year }\end{array}$} & \multicolumn{2}{|c|}{ Univariate analysis against } \\
\hline & & & & & Department group & SSI \\
\hline & & $<50 /$ year & 50-100/year & $>100 /$ year & $p$ value & $p$ value \\
\hline Department, N & 74 & 38 & 16 & 20 & & \\
\hline \multicolumn{7}{|l|}{ Department characteristics } \\
\hline Mean of number of beds & 409.5 & 315 & 449.4 & 557 & $<0.0001$ & \\
\hline Number of teaching hospitals & 4 & 0 & 0 & 4 & 0.0012 & \\
\hline Number of tertiary hospitals & 21 & 5 & 6 & 10 & 0.0074 & \\
\hline Number of cancer centers & 3 & 0 & 1 & 2 & 0.11 & \\
\hline \multicolumn{7}{|l|}{ Thoracic surgery } \\
\hline Total number (from 2014 to 2018) & 26,878 & 3086 & 5718 & 18,074 & & \\
\hline Number of surgical site infections & 335 & 43 & 60 & 232 & & \\
\hline Rate of surgical site infections (\%) & 1.25 & 1.39 & 1.05 & 1.28 & & \\
\hline Median number of procedures / year & 72.6 & 11.8 & 68.6 & 145.2 & & \\
\hline \multicolumn{7}{|l|}{ Open thoracic surgery } \\
\hline Procedures & 5724 & 841 & 1051 & 3832 & & \\
\hline Number of surgical site infections & 100 & 10 & 25 & 65 & & \\
\hline Rate of surgical site infections (\%) & 1.75 & 1.12 & 2.38 & 1.7 & & \\
\hline Video-assisted thoracic surgery (VATS) & & & & & $<0.0001$ & 0.0001 \\
\hline Procedures & 21,154 & 2245 & 4667 & 14,242 & & \\
\hline Number of surgical site infections & 235 & 33 & 35 & 167 & & \\
\hline Rate of surgical site infections (\%) & 1.11 & 1.47 & 0.75 & 1.17 & & \\
\hline Age (median, IQR) & $68(55-74)$ & $63(27-73)$ & $68(57-75)$ & $68(59-74)$ & $<0.0001$ & 0.06 \\
\hline Sex & & & & & $<0.0001$ & $<0.0001$ \\
\hline Female & 7345 (34.7\%) & $582(25.9 \%)$ & 1575 (33.7\%) & $5188(36.4 \%)$ & & \\
\hline Male & $13,809(65.3 \%)$ & $1663(74.1 \%)$ & $3092(66.3 \%)$ & $9054(63.6 \%)$ & & \\
\hline Emergency operation & & & & & $<0.0001$ & 0.605 \\
\hline Yes & $1187(5.6 \%)$ & $264(11.8 \%)$ & 152 (3.3\%) & 771 (5.4\%) & & \\
\hline No & 19,967 (94.4\%) & 1981 (88.2\%) & 4515 (96.7\%) & 13,471 (94.6\%) & & \\
\hline NNIS risk index & & & & & $<0.0001$ & $<0.0001$ \\
\hline 0 & 14,160 (66.9\%) & 1601 (71.3\%) & 2415 (51.7\%) & 10,144 (71.2\%) & & \\
\hline 1 & $6343(30.0 \%)$ & $565(25.2 \%)$ & 2001 (42.9\%) & 3777 (26.5\%) & & \\
\hline 2,3 & $651(3.1 \%)$ & $78(3.5 \%)$ & $251(5.4 \%)$ & $321(2.3 \%)$ & & \\
\hline
\end{tabular}

NNIS National Nosocomial Infections Surveillance System, SSI surgical site infections

Multiple logistic regression analysis stratified by the NNIS risk index

We conducted multiple logistic regression analyses controlling for confounding factors. Specifically, sex was added as a covariate, and the data were stratified by the NNIS risk index, enabling estimation of the OR for each NNIS risk index. The results revealed a statistically significant association between the department groups and SSI in the strata of NNIS risk indices 1 and 2-3 (Table 3), but not in the stratum of NNIS risk index 0 . In the strata of NNIS risk indices 1 and 2-3, the risk of
SSI was always the lowest in the group with a moderatefrequency of surgeries. When the group with a moderate-frequency of surgeries was used as a reference, both the groups with low- (OR: 2.48 [95\% CI 1.20-5.13], $P=0.0143$ ) and high- (OR: 2.43 [95\% CI 1.44-4.11], $P=$ $0.0009)$ frequency of surgeries were significantly positively associated with SSI in the stratum of NNIS risk index 1. A similar association was found between SSI and male sex (OR: 2.13 [95\% CI 1.31-3.48] $P=0.0024$ ). In the stratum of NNIS risk indices 2 and 3, only the group with a low frequency of surgeries was significantly 
Table 3 Multiple logistic regression analysis stratified by the NNIS risk index

\begin{tabular}{llll}
\hline & OR & $\mathbf{9 5 \%}$ Cl & $\boldsymbol{p}$ value \\
\hline NNIS risk index 1 group & & & \\
Male sex & 2.13 & $1.31-3.48$ & 0.0024 \\
Age & 1.02 & $1.01-1.03$ & 0.0021 \\
$\quad<$ 50/year & 2.48 & $1.20-5.13$ & 0.0143 \\
50-100/year & Reference & Reference & Reference \\
$>$ 100/year & 2.43 & $1.44-4.11$ & 0.0009 \\
NNIS risk indices 2-3 group & & \\
Male sex & & & 0.063 \\
Age & & & 0.65 \\
$\quad<$ 50/year & 4.83 & $1.47-15.93$ & 0.0095 \\
50-100/year & Reference & Reference & Reference \\
$>$ 100/year & & & 0.21 \\
\hline
\end{tabular}

NNIS National Nosocomial Infections Surveillance System

positively associated with SSI (OR: 4.83, 95\% CI: $1.47-$ 15.93, $P=0.0095$ ). (Table 3).

\section{Discussion}

The association between the frequency of surgeries and the incidence of SSIs in VATS is yet to be clarified. Our study revealed that low- and high-frequency of surgeries were associated with significantly higher rates of SSIs than moderate-frequency of surgeries in the cases with NNIS risk index 1. Meanwhile, in the cases of NNIS risk index 2 or 3, a low-frequency of surgeries was associated with significantly higher rate of SSIs. To the best of our knowledge, this is the first study to investigate the relationship between the frequency of surgeries and SSIs in THOR procedures based on a large national surveillance database. After focusing on VATS, which accounted for most procedures and was found to be a confounding factor, we found a significant association between the stratum of NNIS risk index 1 and that of NNIS risk indices $2-3$.

The frequency of surgeries was classified using the total number of procedures, including VATS and open thoracic surgery. Further, similar results were obtained if only the annual number of VATS procedures was used, with the multiple logistic regression analysis adjusted for sex and stratified by NNIS risk index (Additional Table 1). A high-frequency of surgeries was significantly positively associated with SSIs in the stratum of NNIS risk index 1 (OR: 1.94 [95\% CI 1.20-3.15], $P=0.0066$ ). In the stratum of NNIS risk indices 2 and 3, only the lowfrequency of surgeries was significantly positively associated with SSI (OR: 3.76, 95\% CI: 1.25-11.26, $P=0.0181$ ).

Superficial and deep incisional infections accounted for $51.6 \%$ of all SSIs, indicating that both VATS and open thoracic surgeries influenced the incidence of SSI.
Okada et al. reported the effectiveness of hybrid videoassisted thoracic surgery, a combination of VATS and open thoracic surgery (5-year overall survival: $89.8 \%$, 5year disease-free survival: $84.7 \%$ ) [24], supporting the importance of both VATS and thoracic surgery in general. Therefore, we considered that the result using the average number of all kinds of procedures annually as a measure of the frequency of a department's surgeries would be more accurate than that confined to VATS.

In general, it is expected that a higher frequency of surgeries would be associated with a lower risk of SSI. This has been consistently shown in several previous studies that examined the association between frequency of surgeries and SSI rates in other types of surgeries [23, 25]. However, our study revealed that the group with the moderate- frequency of surgeries had the lowest risk of SSIs in the NNIS risk index 1 stratum. To our best knowledge, this is the first study to report such a finding. This result could be explained by the significantly higher proportion of the teaching hospitals and tertiary hospitals in the highfrequency of surgeries group than in the other groups. Previously, Mu et al. analyzed the NHSN SSI surveillance data, including thoracic surgeries, and reported that a bed number greater than 500 was associated with a significantly higher SSI risk after adjusting for other risk factors [9]. The present study is consistent with these findings, but further revealed that hospitals conducting a high frequency of surgeries had a significantly higher number of beds and were more likely to be teaching and tertiary hospitals than others (Table 2). Teaching and tertiary hospitals are responsible for training doctors, which could inadvertently cause a higher incidence of SSI in the NNIS risk index 1. Another possible explanation is the higher proportion of complicated cases or organized infection control teams that can report SSI without omissions, although such data are not available.

This result is somewhat consistent with those reported by Furuya-Kanamori et al., who showed that the groups with a high-frequency of surgeries tended to have a higher risk of SSI than the groups with a low-frequency of surgeries in colorectal surgeries, although they did not stratify and control for the risk index [16]. Meanwhile, in the stratum of NNIS risk indices $2-3$, there was no significant difference between the middle and high-frequency of surgeries groups, perhaps because experienced instructors, rather than inexperienced ones, could be responsible for the operations of complicated cases in the group with the high-frequency of surgeries. Umana-Pizano et al. reported a difference in outcomes following acute type A dissection between surgeons with low-frequency of surgeries and those with highfrequency of surgeries in high-frequency of surgeries centers [26]. To the best of our knowledge, all studies that examined the relationship between surgery and the 
rate of SSIs were reported from high-income countries. There was no SSI surveillance system in low- and middle-income countries [18]. Anderson et al. reported a relationship between the frequency of surgeries and postoperative mortality rate in a single center and the difficulty of collecting data in low-income countries [27].

The other risk factor of SSI in NNIS risk index 1 was the male sex. Based on analyses using the German national nosocomial surveillance system (OP-KISS), Aghdassi et al. reported that the male sex was one of the risk factors for SSIs in orthopedics, traumatology, and abdominal surgeries. Meanwhile, the female sex was one of the risk factors for SSIs in heart and vascular surgeries [19]. Schroder et al. reported that the male sex was one of the risk factors for SSIs in hip prosthesis (OR: 1.28, 95\% CI: $1.11-1.49, P=0.001)$ and colon surgeries (OR: 1.16, 95\% CI: 1.04-1.29, $P<0.001$ ) [28]. However, no previous study has reported its positive association with SSI in THOR procedures. This association could be because smoking is more frequent among men than among women in Japan [29], and is a factor affecting SSI [30].

The surveillance data we analyzed did not include detailed information concerning the comorbidities and clinical background (e.g., Brinkman index) of each patient. Despite this limitation, we utilized the large dataset of 26 , 878 THOR procedures collected from 74 hospitals (departments) across Japan. This number was almost eight-fold higher than that collected (3370 procedures) for 12 years and analyzed in a similar study by Cvijanovic et al. [8] Although they evaluated the risk factors for SSIs in THOR, they did not consider the frequency of surgeries in the analysis. In their study, SSIs occurred in $6.08 \%$ of the 3370 procedures and $2.14 \%$ of 700 VATS procedures. The large dataset enabled us to elucidate the effect of the frequency of surgeries on SSI stratified by the NNIS risk index. Further, our analysis of the SSI surveillance data focusing on the THOR procedures quantified the effect of the frequency of surgeries per department on SSIs after carefully adjusting for confounding factors, including VATS.

\section{Conclusion}

In conclusion, in the stratum of NNIS risk index 1, SSI incidence was the lowest in the departments with a moderate frequency of surgeries. Meanwhile, in the stratum of NNIS risk indices 2-3, SSI incidence was the lowest in the departments with moderate- and high-frequency of surgeries. These results suggest that for departments with a lowfrequency of surgeries, an increase in the frequency of surgeries to $>50$ per department per year potentially leads to a decrease in the incidence of SSIs. This would occur through an increase in the experience of surgeons in the departments and contribute to the improvement of VATS outcomes in thoracic surgeries.

\section{Abbreviations}

Cl: Confidence interval; JANIS: Japan Nosocomial Infections Surveillance; NNIS: National Nosocomial Infections Surveillance System; ORs: Odds ratios; SSIs: Surgical site infections; THOR: Thoracic surgeries; VATS: Video-assisted thoracic surgeries

\section{Supplementary Information}

The online version contains supplementary material available at https://doi. org/10.1186/s12879-021-06050-6.

Additional file 1: Figure 1. Average number of annual procedures per department of 74 hospitals. The vertical axis shows the number of procedures, and the horizontal axis shows the number of hospitals.

Additional file 2: Table 1. Multiple logistic regression analysis of risk factors of THOR, including VATS.

\section{Acknowledgments}

We are grateful to all the hospitals that participated and contributed data to JANIS; we are also grateful to Editage (www.editage.jp) for English language editing.

\section{Authors' contributions}

TK and KY designed the study, collected and analyzed the data, and wrote the manuscript. $\mathrm{AH}, \mathrm{HK}, \mathrm{MS}$, and $\mathrm{KS}$ interpreted the results and reviewed the final draft of the manuscript. All authors read and revised the final manuscript for critical intellectual content. The authors read and approved the final manuscript

\section{Funding}

This study was also supported by the Research Program on Emerging and Re-emerging Infectious Diseases from the Japanese Agency for Medical Research and Development (AMED) under grant number 19fk0108061j0002.

\section{Availability of data and materials}

The datasets generated and analyzed during the current study are available at [https://figshare.com/s/09227b8064aee2e8881c].

\section{Declarations}

\section{Ethics approval and consent to participate}

Patient identifiers were de-identified by each hospital before data submission to JANIS. The anonymous data stored in the JANIS database were exported and analyzed.

The protocol of this study was approved by the Ministry of Health, Labor and Welfare (approval number 0417-1) according to Article 32 of the Statistics Act and in accordance with the Helsinki Declaration. The requirement for informed consent was waived by the Ministry of Health, Labor and Welfare (approval number 0417-1).

\section{Consent for publication}

Not applicable.

\section{Competing interests}

The authors declare that they have no competing interests.

\section{Author details}

${ }^{1}$ Antimicrobial Resistance Research Center, National Institute of Infectious Diseases, 4-2-1 Aoba-cho Higashimurayama, Tokyo 189-0002, Japan.

${ }^{2}$ Department of Bacteriology II, National Institute of Infectious Diseases, 4-7-1 Gakuen Musashimurayama, Tokyo 280-0011, Japan.

Received: 29 January 2021 Accepted: 5 April 2021

Published online: 17 April 2021

\section{References}

1. Raman V, Yang CJ, Deng JZ, D'Amico TA. Surgical treatment for early stage non-small cell lung cancer. J Thorac Dis. 2018;10(Suppl 7):S898-904. https:// doi.org/10.21037/jtd.2018.01.172. 
2. Committee for Scientific Affairs TJAfTS, Shimizu H, Okada M, Toh Y, Doki Y, Endo S, et al. Thoracic and cardiovascular surgeries in Japan during 2018 : Annual report by the Japanese Association for Thoracic Surgery. Gen Thorac Cardiovasc Surg. 2021;69(1):179-212.

3. Magill SS, Edwards JR, Bamberg W, Beldavs ZG, Dumyati G, Kainer MA, et al. Multistate point-prevalence survey of health care-associated infections. N Engl J Med. 2014;370(13):1198-208. https://doi.org/10.1056/NEJMoa1306801.

4. Suetens C, Latour K, Karki T, Ricchizzi E, Kinross P, Moro ML, Jans B, Hopkins S, Hansen S, Lyytikainen O, et al. Prevalence of healthcareassociated infections, estimated incidence and composite antimicrobial resistance index in acute care hospitals and long-term care facilities: results from two European point prevalence surveys, 2016 to 2017. Euro Surveill. 2018;23(46): 1800516.

5. Cassini A, Plachouras D, Eckmanns T, Abu Sin M, Blank HP, Ducomble T, et al. Burden of six healthcare-associated infections on European population health: estimating incidence-based disability-adjusted life years through a population prevalence-based Modelling study. PLoS Med. 2016;13(10): e1002150. https://doi.org/10.1371/journal.pmed.1002150.

6. Juchler F, Roth JA, Schweiger A, Dangel M, Gugliotta M, Battegay M, et al. Costs versus earnings in colon surgery and coronary artery bypass grafting under a prospective payment system: sufficient financial incentives to reduce surgical site infections? Infect Control Hosp Epidemiol. 2018;39(10): 1246-9. https://doi.org/10.1017/ice.2018.179.

7. McFarland A, Reilly J, Manoukian S, Mason H. The economic benefits of surgical site infection prevention in adults: a systematic review. J Hosp Infect. 2020;106(1):76-101. https://doi.org/10.1016/j.jhin.2020.05.011.

8. Cvijanovic VS, Ristanovic AS, Maric NT, Vesovic NV, Kostovski W, Djenic LV, et al. Surgical site infection incidence and risk factors in thoracic surgical procedures: a 12-year prospective cohort study. J Infect Dev Ctries. 2019; 13(3):212-8. https://doi.org/10.3855/jidc.11240.

9. Mu Y, Edwards JR, Horan TC, Berrios-Torres SI, Fridkin SK. Improving riskadjusted measures of surgical site infection for the national healthcare safety network. Infect Control Hosp Epidemiol. 2011;32(10):970-86. https:// doi.org/10.1086/662016.

10. Ezer N, Kale M, Sigel K, Lakha S, Mhango G, Goodman E, et al. Outcomes after video-assisted thoracoscopic lobectomy versus open lobectomy for early-stage lung Cancer in older adults. Ann Am Thorac Soc. 2018;15(1):7682. https://doi.org/10.1513/AnnalsATS.201612-9800C.

11. Muilwijk J, van den Hof S, Wille JC. Associations between surgical site infection risk and hospital operation volume and surgeon operation volume among hospitals in the Dutch nosocomial infection surveillance network. Infect Control Hosp Epidemiol. 2007;28(5):557-63. https://doi.org/10.1086/ 513613.

12. Yu TH, Tung YC, Chung KP. Which kind of Provider's operation volumes matters? Associations between CABG surgical site infection risk and hospital and surgeon operation volumes among medical centers in Taiwan. PLoS One. 2015;10(6):e0129178. https://doi.org/10.1371/journal.pone.0129178.

13. Aghdassi SJS, Gastmeier P. Novel approaches to surgical site infections: what recommendations can be made? Expert Rev Anti-Infect Ther. 2017; 15(12):1113-21. https://doi.org/10.1080/14787210.2017.1404451.

14. Rimmer L, Elsantawy $H$, Harky A, Bashir M. Volume-outcome relationship in type a aortic dissection: crosswords or crossroads? J Thorac Dis. 2020;12(6): 3433-5. https://doi.org/10.21037/jtd.2020.01.46.

15. Wu SC, Chen CC, Ng YY, Chu HF. The relationship between surgical site infection and volume of coronary artery bypass graft surgeries: Taiwan experience. Infect Control Hosp Epidemiol. 2006;27(3):308-11. https://doi. org/10.1086/503015.

16. Furuya-Kanamori L, Doi SAR, Smith PN, Bagheri N, Clements ACA, Sedrakyan A. Hospital effect on infections after four major surgical procedures: outlier and volume-outcome analysis using all-inclusive state data. J Hosp Infect. 2017:97(2):115-21. https://doi.org/10.1016/j.jhin.2017.05.021.

17. Morikane $\mathrm{K}$, Honda H, Yamagishi T, Suzuki S. Differences in risk factors associated with surgical site infections following two types of cardiac surgery in Japanese patients. J Hosp Infect. 2015;90(1):15-21. https://doi. org/10.1016/j.jhin.2014.11.022.

18. Takaya S, Hayakawa K, Matsunaga N, Moriyama Y, Katanami Y, Tajima T, et al. Surveillance systems for healthcare-associated infection in high and upper-middle income countries: a scoping review. J Infect Chemother. 2020; 26(5):429-37. https://doi.org/10.1016/j.jiac.2020.01.001.

19. Aghdassi SJS, Schroder C, Gastmeier P. Gender-related risk factors for surgical site infections. Results from 10 years of surveillance in Germany.
Antimicrob Resist Infect Control. 2019;8(1):95. https://doi.org/10.1186/s13 756-019-0547-x.

20. Edwards JR, Peterson KD, Mu Y, Banerjee S, Allen-Bridson K, Morrell G, et al. National Healthcare Safety Network (NHSN) report: data summary for 2006 through 2008, issued December 2009. Am J Infect Control. 2009;37(10):783805. https://doi.org/10.1016/j.ajic.2009.10.001.

21. Morikane K, Honda H, Yamagishi T, Suzuki S, Aminaka M. Factors associated with surgical site infection in colorectal surgery: the Japan nosocomial infections surveillance. Infect Control Hosp Epidemiol. 2014;35(6):660-6. https://doi.org/10.1086/676438.

22. Culver DH, Horan TC, Gaynes RP, Martone WJ, Jarvis WR, Emori TG, et al. Surgical wound infection rates by wound class, operative procedure, and patient risk index. National Nosocomial Infections Surveillance System. Am J Med. 1991;91(3B):152S-7S. https://doi.org/10.1016/0002-9343(91)90361-Z.

23. Meyer E, Weitzel-Kage D, Sohr D, Gastmeier P. Impact of department volume on surgical site infections following arthroscopy, knee replacement or hip replacement. BMJ Qual Saf. 2011;20(12):1069-74. https://doi.org/1 0.1136/bmjqs.2011.051250.

24. Okada M, Tsutani Y, Ikeda T, Misumi K, Matsumoto K, Yoshimura M, et al. Radical hybrid video-assisted thoracic segmentectomy: long-term results of minimally invasive anatomical sublobar resection for treating lung cancer. Interact Cardiovasc Thorac Surg. 2012;14(1):5-11. https://doi.org/10.1093/ icvts/ivr065.

25. Calderwood MS, Kleinman K, Huang SS, Murphy MV, Yokoe DS, Platt R. Surgical site infections: volume-outcome relationship and year-to-year stability of performance rankings. Med Care. 2017;55(1):79-85. https://doi. org/10.1097/MLR.0000000000000620.

26. Umana-Pizano JB, Nissen AP, Sandhu HK, Miller CC, Loghin A, Safi HJ, et al. Acute type a dissection repair by high-volume Vs low-volume surgeons at a high-volume aortic center. Ann Thorac Surg. 2019;108(5):1330-6. https://doi. org/10.1016/j.athoracsur.2019.04.040.

27. Anderson GA, Ilcisin L, Abesiga L, Mayanja R, Portal Benetiz N, Ngonzi J, et al. Surgical volume and postoperative mortality rate at a referral hospital in Western Uganda: measuring the lancet commission on global surgery indicators in low-resource settings. Surgery. 2017;161(6):1710-9. https://doi. org/10.1016/j.surg.2017.01.009.

28. Schroder C, Schwab F, Behnke M, Breier AC, Maechler F, Piening B, et al. Epidemiology of healthcare associated infections in Germany: nearly 20 years of surveillance. Int J Med Microbiol. 2015;305(7):799-806. https://doi. org/10.1016/j.jmm.2015.08.034.

29. Yamaguchi T, Nishiura H. Predicting the epidemiological dynamics of lung cancer in Japan. J Clin Med. 2019;8(3):326.

30. Gajdos C, Hawn MT, Campagna EJ, Henderson WG, Singh JA, Houston T. Adverse effects of smoking on postoperative outcomes in cancer patients. Ann Surg Oncol. 2012;19(5):1430-8. https://doi.org/10.1245/s10434-011-212 8-y.

\section{Publisher's Note}

Springer Nature remains neutral with regard to jurisdictional claims in published maps and institutional affiliations.

Ready to submit your research? Choose BMC and benefit from:

- fast, convenient online submission

- thorough peer review by experienced researchers in your field

- rapid publication on acceptance

- support for research data, including large and complex data types

- gold Open Access which fosters wider collaboration and increased citations

- maximum visibility for your research: over $100 \mathrm{M}$ website views per year

At $\mathrm{BMC}$, research is always in progress.

Learn more biomedcentral.com/submissions 